\title{
Full-Thickness Hysterocystoplasty for Management of a Large Bladder Defect: Experimental Study in Goats
}

\author{
Mohamed Abdelfattah ABDELRHMAN ${ }^{1)}$, Aiman Mahmoud SEDDEK ${ }^{2) *}$, Hossam Ahmed BAKR ${ }^{3)}$ and \\ Khaled Ali ELNESR ${ }^{4}$ \\ ${ }^{1)}$ Department of Surgery, Anaesthesiology and Radiology, Faculty of Veterinary Medicine, Beni-Suef University, P. O. Box 62511, Beni-Suef, \\ Egypt \\ ${ }^{2)}$ Department of Surgery, Anaesthesiology and Radiology, Faculty of Veterinary Medicine, Sohag University, P. O. Box 82524, Sohag, Egypt \\ ${ }^{3)}$ Department of Animal Medicine, Faculty of Veterinary Medicine, Beni-Suef University, P. O. Box 62511, Beni-Suef, Egypt \\ 4) Department of Pathology, Faculty of Veterinary Medicine, Beni-Suef University, P. O. Box 62511, Beni-Suef, Egypt
}

(Received 4 July 2012/Accepted 17 January 2013/Published online in J-STAGE 31 January 2013)

ABSTRACT. The uterine tissue of three healthy nonpregnant goats was evaluated experimentally as a graft for closure of a bladder defect. Goats were subjected to ovariectomy, and then one detubularized uterine horn was used as a graft to close a large defect in the ventral aspect of the bladder. Follow up included monthly radiographic and ultrasonographic examinations and evaluations of kidney function and electrolytes changes for six months. The goats were euthanized after six months, and both the bladder and the graft were examined macroscopically and histologically. The technique required less invasive procedures than those described with alternative techniques of cystoplasty, achieved a high survival rate without life-threatening complications post surgery, was associated with no significant changes in kidney function and electrolytes levels, showed proper healing of the transplanted graft by regeneration rather than repair without scaring or fibrosis and with complete covering of the graft by a healthy urothelium and was associated with no malignant transformation. Hysterocystoplasty is a noninvasive, non-life-threatening technique due to the close position of the bladder to the uterus, and proper healing of the graft reflects absence of pressure on its blood supply. It is an acceptable alternative technique for closure of a large bladder defect and avoids disadvantages of alternative techniques of cystoplasty. It might be accepted by owners of pets, and further studies in clinical cases of dogs are advised.

KEY WORDS: bladder, goat, hysterocystoplasty, urinary, uterus.

doi: 10.1292/jvms.12-0298; J. Vet. Med. Sci. 75(6): 767-771, 2013

Although cystoplasty is a historic topic that has been discussed well in scientific literature and argued at legendary proportion among urologists, the search for an ideal organ to replace a diseased bladder remains elusive for reconstructive urologists [32]. Many augmentation cystoplasty or neobladder techniques have been used routinely for treatment of reduced bladder compliance and capacity secondary to bladder infection and inflammation [27], neurogenic dysfunction or congenital bladder disorders [16], detrusor over activity [10], large bladder defects [8,9], bladder necrosis [30] and bladder tumors [7, 12]. Although encouraging animal and human results have been reported with different techniques, each technique had its own limitations, complications and disadvantages [2, 4, 11, 27].

The ileum and colon have been used for decades for reconstruction of the bladder, in spite of the harmful contact of urine with the mucosa of the augmenting patch [23], which is predisposed to multiple short- and/or long-term complications like chronic bacteriuria or mucous secretion $[1,23]$, stone formation $[1,11,29]$, disturbance of calciumphosphate metabolism with potential bone growth retarda-

*Correspondence to: Seddek, A. M., Department of Veterinary Surgery, Faculty of Veterinary Medicine, Sohag University, P. O. Box 82524, Sohag, Egypt.

e-mail:mmm_bbb15@yahoo.com

(C)2013 The Japanese Society of Veterinary Science tion [24, 28], altered hepatic and electrolyte metabolism [24], gastrointestinal motility disorders [23], augmenting patch perforation $[1,6]$ and malignant transformation of the augmenting patch $[1,14]$.

Gastrocystoplasty has been described as an alternative technique; unfortunately, as the popularity of gastrocystoplasty increased, so did awareness of its potential complications, like hematuria, stricture, rupture of the gastric segment, adenocarcinoma formation and hypochloremic alkalosis, which is much more difficult to treat than chronic metabolic acidosis. Accordingly, gastrocystoplasty is no longer a safe method for bladder augmentation $[4,11,26]$.

In an attempt to prevent the nonphysiological contact between urine and the bowel mucosa, several techniques of bladder augmentation have been assessed in experimental and clinical studies, and as no final statement emerged from these trials, we decided to evaluate experimentally the outcome of incorporating a detubularized uterine horn in the bladder and the potential of in vivo urothelium growth onto this uterine patch. The technique was evaluated experimentally in nonpregnant goats after partial cystectomy of about $40 \%$ of the bladder wall through its ventral aspect.

\section{MATERIALS AND METHODS}

Three nonpregnant goats were used in the present study. The goats were cared for according to the principles of the Guide for the Care and Use of Laboratory Animals prepared 
by Beni-Suef University. The Animal Care and Use Committee of Beni-Suef University approved the study. The goats were anesthetized with intravenous diazepam $(0.5 \mathrm{mg} / \mathrm{kg}$, Valipam ${ }^{\circledR}$, Amoun Pharmaceuticals Co., Cairo, Egypt), intramuscular xylazine hydrochloride $\left(0.2 \mathrm{mg} / \mathrm{kg}\right.$, Xyla-Ject ${ }^{\circledR}$, ADWIA Pharmaceuticals Co., Cairo, Egypt) and local linear analgesia using lidocaine hydrochloride 2\% (about 10-15 ml, Debocaine ${ }^{\circledR}$, Sigma-Tec Pharmaceuticals Industries Co., Cairo, Egypt) at the site of celiotomy, a midline incision was created at the prepubic region to exteriorize the urinary bladder and the uterus, and bilateral ovariectomy was performed (Fig. 1a). One horn of the uterus was grasped and ligated, anterior and posterior to the site prepared for creating an augmenting flap. The greater curvature of that horn was incised longitudinally to create an augmenting flap (Fig. 1b) that was disinfected with povidone iodine 10\% (Betadine ${ }^{\circ}$, Nile Co. for Pharmaceutical and Chemical Industries, Cairo, Egypt), and the two stomas created in the uterine mucosa were closed by purse-string sutures (Fig. 1c). The far side of the uterine flap was advanced gently and fixed to the ventral aspect of the bladder, by using $2-0$ polyglactin 910 (Vicryl, ETHICON, Johnson \& Johnson Medical Limited, Livingston, U.K.), in an interrupted manner (Fig. 1c), about $40 \%$ of the bladder wall was excised and the near side of the flap was fixed to close the created defect in the bladder (Fig. 1d-f). The abdomen was closed in layers, and aftercare of the animal included intramuscular injection of $20 \%$ oxytetracycline $(10 \mathrm{mg} / \mathrm{kg}$, Terramycin LA, Pfizer Egypt, Cairo, Egypt) every three days with two successive doses and frequent aseptic catheterization of the bladder for one week.

Blood samples were collected before surgery, and every month till the 6th month, and ultrasonographic and radiographic evaluations of the bladder were performed every month post surgery till euthanasia of the animals at six months post surgery. Then, the transplanted uterine horn, the bladder and the kidneys were fixed in $10 \%$ neutral formalin and processed for routine histologic examination. Five- to seven-micrometer sections were stained with hematoxylin and eosin and Masson's trichrome stains [5].

Biochemical parameters of blood samples were analyzed statistically by one-way analysis of variance (ANOVA).

\section{RESULTS}

The technique was simple, easy and non-invasive and did not strain of the blood supply of the transplanted graft, and all the operated goats were in good health, completed the period of the experiment ( 6 months) and showed a normal urination frequency by the week after surgery.

Blood analysis monthly for six months (Table 1) revealed no significant changes in total protein, albumen, urea, creatinine and electrolytes levels.

Ultrasonographic and radiographic investigations revealed no rejection or perforation of the transplanted uterine flap, no stone formation, absence of signs of chronic inflammation and increased capacity of the bladder of over time (Fig. 2a and 2b).

Gross postmortem examination of the harvested bladder at six months post surgery revealed absence of macroscopic lesions in the kidneys or urinary tract. The outer and inner surfaces of the transplanted graft showed no necrosis, atrophy, perforation or rejection. The anastomotic line seemed smooth, and the two sutured stomas on the inner surface (mucosa) appeared as tiny depressions that neither connected to the uterine body nor to the tip of horn (Fig. 2c and 2d).

Histologically, all the three layers of the uterine graft (Fig. 3a) and native bladder tissue preserved their normal architecture and were in an organized pattern. The endometrium was completely covered with multiple layers of transitional epithelium (Fig. 3b), which had a thickness similar to that covering the native bladder.

At the anastomotic site, the suture line was indefinitive, and there was no scarring; complete healing was evident, with early development of muscle growth of the existing muscles in the graft towards the bladder wall (Fig. 3c and 3d).

Submucosal neovascularization was seen in all cases in variably sized blood vessels, which were randomly distributed in the area of graft (Fig. 3e and 3f), but congestion was rarely found. Smooth muscle fibers were organized and showed no degeneration, necrosis or calcinosis. Stromal

Table 1. Mean $\pm \mathrm{SD}$ of serum biochemical parameters of operated goats over six months

\begin{tabular}{|c|c|c|c|c|c|c|c|}
\hline $\begin{array}{l}\text { Date of sampling } \\
\text { Parameters }\end{array}$ & Before surgery & 1st month & 2nd month & 3rd month & 4th month & 5th month & 6th month \\
\hline Serum total protein $(\mathrm{g} / \mathrm{d} l)$ & $6.63 \pm 0.15$ & $6.53 \pm 0.06$ & $6.4 \pm 0.17$ & $6.6 \pm 0.10$ & $6.43 \pm 0.25$ & $6.5 \pm 0.17$ & $6.47 \pm 0.06$ \\
\hline Serum albumin $(\mathrm{g} / \mathrm{d} l)$ & $2.53 \pm 0.06$ & $2.67 \pm 0.15$ & $2.53 \pm 0.15$ & $2.57 \pm 0.25$ & $2.6 \pm 0.10$ & $2.6 \pm 0.10$ & $2.47 \pm 0.25$ \\
\hline Serum urea $(\mathrm{mg} / \mathrm{d} l)$ & $34.33 \pm 2.08$ & $33.67 \pm 7.09$ & $34.33 \pm 4.04$ & $37 \pm 1.73$ & $37.33 \pm 2.52$ & $36.67 \pm 3.79$ & $36.33 \pm 1.53$ \\
\hline Serum creatinine $(\mathrm{mg} / \mathrm{d} l)$ & $0.77 \pm 0.03$ & $0.77 \pm 0.03$ & $0.77 \pm 0.02$ & $0.74 \pm 0.02$ & $0.76 \pm 0.02$ & $0.77 \pm 0.03$ & $0.76 \pm 0.03$ \\
\hline Serum calcium $(\mathrm{mg} / \mathrm{d} l)$ & $9.33 \pm 0.42$ & $9.3 \pm 0.35$ & $9.37 \pm 0.35$ & $9.2 \pm 0.40$ & $9.3 \pm 0.56$ & $9.37 \pm 0.45$ & $9.4 \pm 0.52$ \\
\hline Serum phosphorus (mg/d $l$ ) & $4.73 \pm 0.15$ & $4.47 \pm 0.15$ & $4.53 \pm 0.15$ & $4.5 \pm 0.26$ & $4.6 \pm 0.10$ & $4.5 \pm 0.20$ & $4.53 \pm 0.15$ \\
\hline Serum sodium $(\mathrm{mmol} / \mathrm{l})$ & $146 \pm 3.00$ & $145 \pm 2.00$ & $144.3 \pm 2.08$ & $145.6 \pm 1.53$ & $143 \pm 1.73$ & $145 \pm 1.00$ & $146 \pm 3.61$ \\
\hline Serum potassium $(\mathrm{mmol} / l)$ & $4.17 \pm 0.15$ & $4.03 \pm 0.12$ & $4.17 \pm 0.06$ & $4.23 \pm 0.15$ & $4.27 \pm 0.15$ & $4.17 \pm 0.15$ & $4.17 \pm 0.31$ \\
\hline
\end{tabular}

Statistical analysis was performed by one-way analysis of variance (ANOVA). The mean difference was considered to be significant at the 0.05 level. There was no statistical difference during the period of the experiment. 


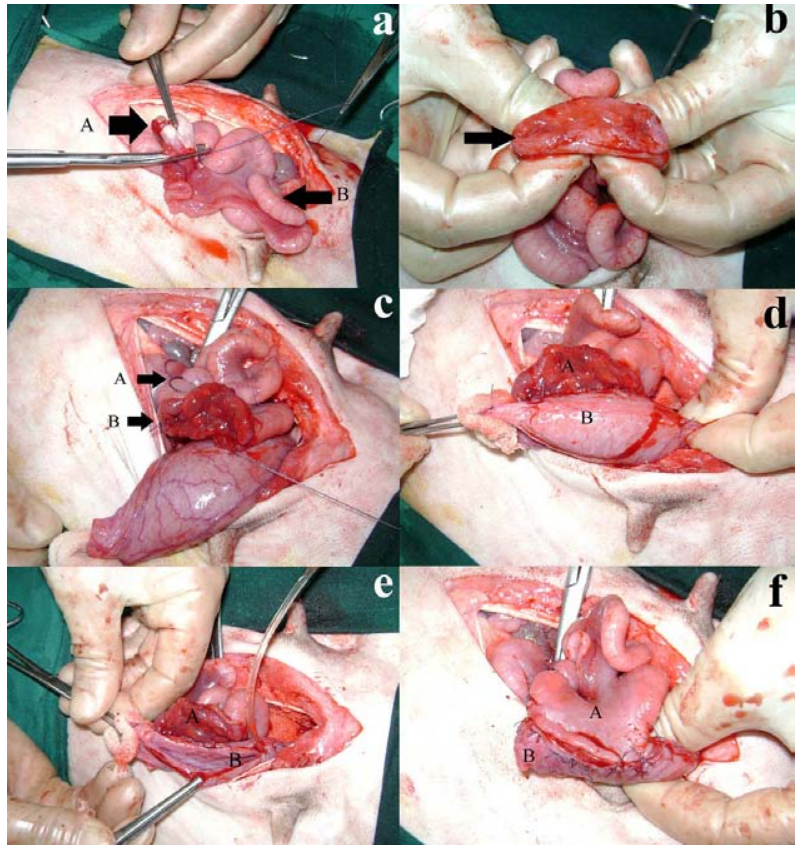

Fig. 1. Surgical procedure of full-thickness hysterocystoplasty. a) Ovariectomy (A, ovary; B, uterine horn). b) Detubularization of a uterine horn (arrow denotes the created stoma in the uterine mucosa). c) Suturing of the far side of the uterine graft to the bladder (A, site of ligation; B, site of purse-string suture). d) Complete suturing of the far side of the graft and circumscribed incision of $40 \%$ of the ventral bladder wall (A, graft; B, bladder). e) Excision of $40 \%$ of the bladder through its ventral aspect (A, graft; B, bladder). f) Complete closure of a bladder defect by a uterine graft (A, graft; B, bladder).

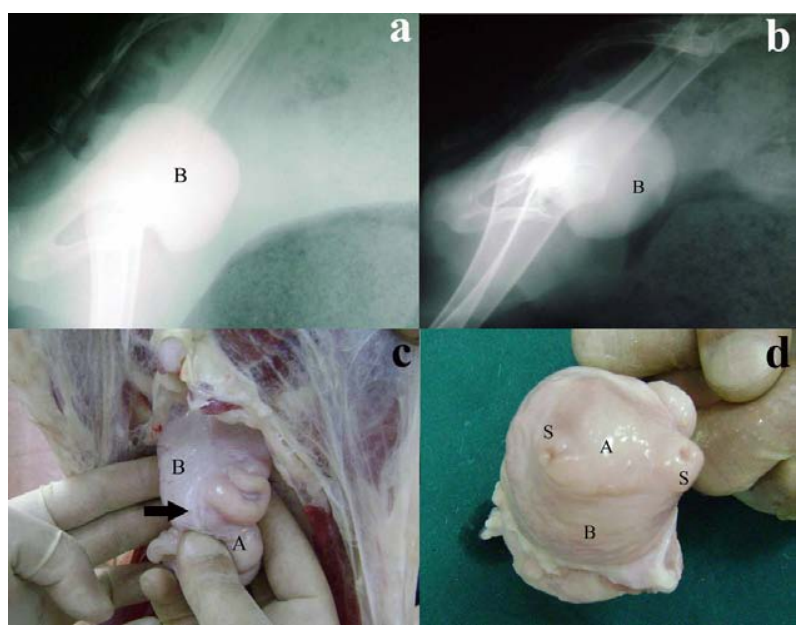

Fig. 2. Cystography and postmortem findings. Lateral view cystography (retrograde by positive contrast) at 2 months (a) and 6 months (b) after the surgery (B, bladder). Postmortem examination was performed at 6 months after surgery. Outer (c) and inner surfaces (d) of the graft showed complete healing (arrow). A: graft. B: bladder. S: site of purse-string suture.

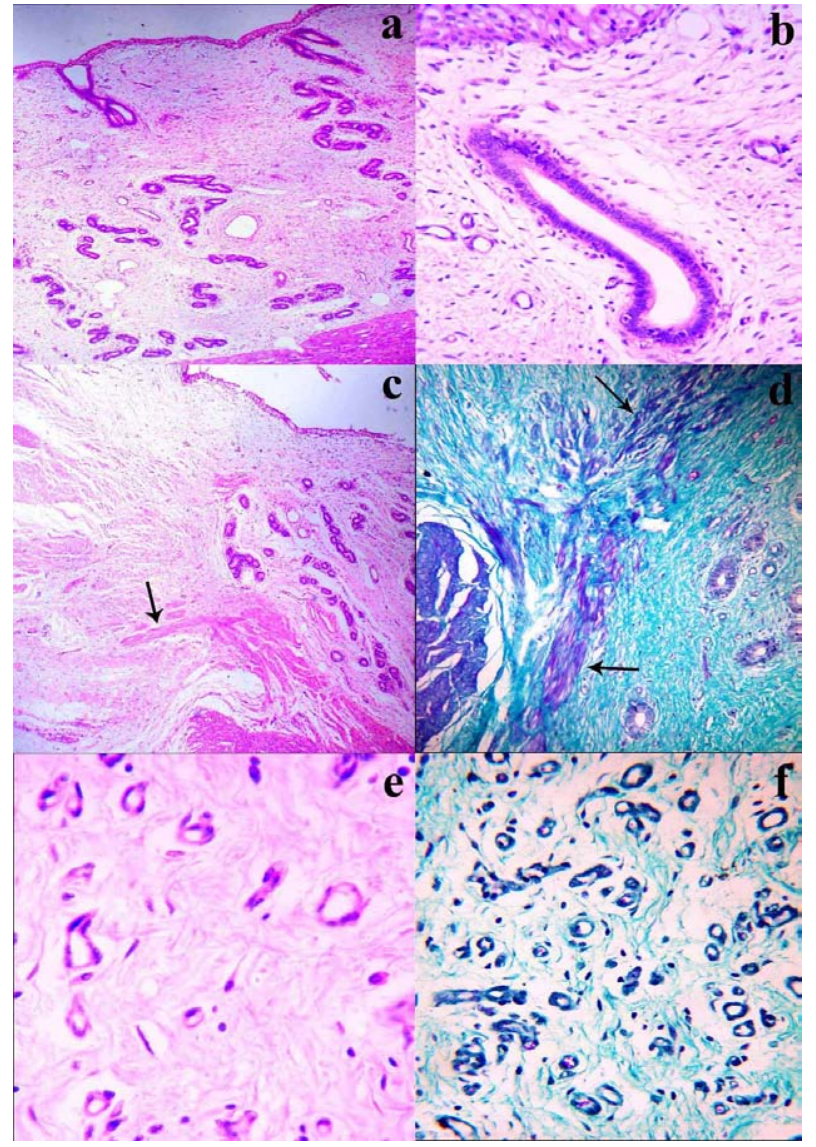

Fig. 3. Histopathological findings of a uterine graft. The uterine graft showed a well-preserved endometrium and myometrium (a: Hematoxyline-Eosin [HE] stain, $\times 100$ ). The luminal surface of the uterine graft was covered by the urothelium (b: HE stain, $\times 200$ ). The anastomosing site showed complete healing (c: HE stain, $\times 100$, arrow denotes early developed smooth muscles), early development of smooth muscle growth (d: two black arrows; trichrome stain, $\times 100$ ), and neovascularization (e: HE stain, $\times 400$ ) (f: trichrome stain, $\times 200$ ).

changes were demonstrated by using trichrome staining, which showed components of collagenous and smooth muscles. Pathological alterations at the level of the kidneys could not be detected in the three goats.

\section{DISCUSSION}

The success rate of a surgical technique is no longer measured by survival rate only; it is also measured by its advantages. In this study, hysterocystoplasty showed a high survival rate and achieved many advantages over gastrocystoplasty or enterocystoplasty.

Use of the uterine horn, which is an organ near the bladder, avoided the possibility of tension on the vascular pedicle of the graft caused by the surrounding organs, which is observed with gastrocystoplasty [32]. Moreover, it neither secretes acid nor alkaline secretions; accordingly, it does 
not alter electrolytes or the acid-base balance and is not associated with high morbidity, which is seen with gastrocystoplasty. It should be noted that gastrocystoplasty has been performed in dogs, but the reported postoperative morbidity associated with this procedure makes it unacceptable to most pet owners [25, 31].

Hysterocystoplasty overcomes disadvantages of enterocystoplasty, as it requires no resection of the bowel, which results in subsequent high morbidity of bowel obstruction or gastrointestinal motility disorders [17, 23, 27], is suitable for patients with a short bowel [20,31], does not alter electrolytes or the acid base balance $[24,31]$ and secretes no mucous; accordingly, it does not cause complications of catheter functions $[1,23,31]$.

It should be noted that the mucosa of the genital system tolerates the harmful irritating effect of urine, and this might be the main cause of absence of malignant transformation six months post surgery, which differs from the case of gastric or bowel tissue, which showed significant ability for growth of malignant tumors [13, 21, 31].

From a histopathological point of view, regeneration of bladder tissue should safely occur without evidence of graft rejection, shrinkage or systemic or bladder-related complications, such as upper tract dilatation, discontinuous urinary flow, fistula, bladder infection or calculi formation [19]. The absence of chronic cystitis in this study, which is one of the most leading causes of failure of bladder augmentation, can be explained in the light of good regeneration of the urothelium that started at the adjacent edges of the native bladder [33], subsequently rested on the basement membrane after completely covering the graft and gradually developed into a urothelium resembling a normal bladder epithelium [15]. This newly formed urothelium maintained a tight permeability barrier, and damage to it predisposes it to leakage of urine components into the underlying bladder layers, leading to symptoms of cystitis [22] or absorption of urine with subsequent alteration of urea and creatinine levels. However, in this study, neither cystitis nor alteration of kidney function could be detected.

It is well documented that inadequate angiogenesis and cellular repopulation are the most common causes of scaring or shrinkage of a graft [3]; however, absence of these signs in our study might be due to the presence of well-developed small and large blood vessels at the anastomotic site and uterine graft. At the same time, the elasticity of the nonshrunken graft should be preserved; this is directly related to development of well-developed and organized smooth muscle bundles derived from the edges of the bladder that traverse the graft, organize and then develop into mature muscles [18].

Absence of graft rejection or shrinkage, preservation of histological structures of the graft and the native bladder tissues, absence of malignant transformation, development of the urothelium over the uterine graft, presence of well-developed neovascularization and presence of well-organized smooth muscle indicate the good prognosis of our technique after six months. We concluded that the full-thickness hysterocystoplasty technique is a simple and easy technique suitable for augmentation of the bladder, overcomes disadvantages of gastrocystoplasty or enterocystoplasty and causes no serious life-threatening complications. The autograft was accepted easily by the bladder without scarring or metaplastic transformation more than six months after surgery. With respect to disadvantages of the technique, it can be used for female only, and operated animals cannot be used for breeding. Accordingly, it is acceptable under limited conditions, and a further study is required to apply the technique in intact pets or humans.

\section{REFERENCES}

1. Abdelmalak, J. B., Vasavada, S. P. and Rackley, R. R. 2003 Bladder reconstruction using bowel segments. Clin. Colon Rectal Surg. 16: 51-60. [CrossRef]

2. Aminsharifi, A., Shakeri, S., Yousofzade, J. and Pakbaz, S. 2011. In situ reversed ileocystoplasty for less invasive augmentation cystoplasty: an experimental study. Urol. Int. 86: 273-277. [Medline] [CrossRef]

3. Atala, A., Bauer, S. B., Soker, S., Yoo, J. J. and Retik, A. B. 2006. Tissue-engineered autologous bladders for patients needing cystoplasty. Lancet 367: 1241-1246. [Medline] [CrossRef]

4. Balachandra, B., Swanson, P. E., Upton, M. P. and Yeh, M. M. 2007. Adenocarcinoma arising in a gastrocystoplasty Case report. J. Clin. Pathol. 60: 85-87. [Medline] [CrossRef]

5. Bancroft, G. D. and Stevens, A. 1996. Theory and Practice of Histological Techniques, Fourth edition, Churchill Livingstone, New York.

6. Bauer, S. B., Hendren, W. H., Kozakewich, H., Maloney, S., Colodny, A. H., Mandell, J. and Retik, A. B. 1992. Perforation of the augmented bladder. J. Urol. 148: 699-703. [Medline]

7. Bufkin, B. W., Henderson, R. A., Beard, D. M. and Smith, A. N. 2009. What is your diagnosis? Transitional cell carcinoma in the bladder of a dog. J. Am. Vet. Med. Assoc. 235: 1403-1404. [Medline] [CrossRef]

8. Celayir, S., Büyükünal, S. N., Kiliç, N. and Dervisoglu, S. 1997. Urodynamic investigations in reversed ileal seromuscular enterocystoplasty: an experimental study in a rabbit model. $\mathrm{Br} . \mathrm{J}$. Urol. 79: 883-887. [Medline] [CrossRef]

9. Celayir, S., Kiliç, N., Dervisoglu, S. and Büyükünal, C. 1996. Rectus abdominis muscle flap (RAMF) technique for the management of large bladder defects: urodynamic findings in a rabbit model. Br. J. Urol. 78: 294-297. [Medline] [CrossRef]

10. Chapple, C. R. and Bryan, N. P. 1998. Surgery for detrusor overactivity. World J. Urol. 16: 268-273. [Medline] [CrossRef]

11. Duel, B. P., Gonzalez, R. and Barthold, J. S. 1998. Alternative techniques for augmentation cystoplasty. J. Urol. 159: 998-1005. [Medline] [CrossRef]

12. Gelberg, H. B. 2010. Urinary bladder mass in a dog. Vet. Pathol. 47: 181-184. [Medline] [CrossRef]

13. Gitlin, J. S., Wu, X. R., Sun, T. T., Ritchey, M. L. and Shapiro, E. 1999. New concepts of histological changes in experimental augmentation cystoplasty: Insights into the development of neoplastic transformation at the enterovesical and gastrovesical anastomosis. J. Urol. 162: 1096-1100. [Medline] [CrossRef]

14. Hasegawa, S., Ohshima, S., Kinukawa, T., Matsuura, O., Takeuchi, Y., Hattori, R. and Murakami, S. 1989. Adenocarcinoma of the bladder 29 years after ileocystoplasty. Hinyokika Kiyo 35: 671-674. [Medline]

15. Hicks, R. M. 1975. The mammalian urinary bladder: an accommodating organ. Biol. Rev. Camb. Philos. Soc. 50: 215-246. 
[Medline] [CrossRef]

16. Higuchi, T. T., Granberg, C. F., Fox, J. A. and Husmann, D. A. 2010. Augmentation cystoplasty and risk of neoplasia: fact, fiction and controversy. J. Urol. 184: 2492-2497. [Medline] [CrossRef]

17. Hill, D. E. and Kramer, S. A. 1990. Management of pregnancy after augmentation cystoplasty. J. Urol. 144: 457-459. [Medline]

18. Imamura, M., Kanematsu, A., Yamamoto, S., Kimura, Y., Kanatani, I., Ito, N., Tabata, Y. and Ogawa, O. 2007. Basic fibroblast growth factor modulates proliferation and collagen expression in urinary bladder smooth muscle cells. Am. J. Physiol. Renal Physiol. 293: F1007-F1017. [Medline] [CrossRef]

19. Kropp, B. P., Rippy, M. K., Badylak, S. F., Adams, M. C., Keating, M. A., Rink, R. C. and Thor, K. B. 1996. Regenerative urinary bladder augmentation using small intestine submucosal: urodynamic and histopathological assessment in long-term canine bladder augmentation. J. Urol. 155: 2098-2104. [Medline] [CrossRef]

20. Kurzrock, E. A., Baskin, L. S. and Kogan, B. A. 1998. Gastrocystoplasty: long-term follow-up. J. Urol. 160: 2182-2186. [Medline] [CrossRef]

21. Lane, T. and Shah, J. 2000. Carcinoma following augmentation ileocystoplasty. Urol. Int. 64: 31-32. [Medline] [CrossRef]

22. Lavelle, J., Meyers, S., Ramage, R., Bastacky, S., Doty, D., Apodaca, G. and Zeidel, M. L. 2002. Bladder permeability barrier: recovery from selective injury of surface epithelial cells. Am. J. Physiol. Renal Physiol. 283: F242-F253. [Medline]

23. Lutz, N. and Frey, P. 1995. Enterocystoplasty using modified pedicled, detubularized, de-epithelialized sigmoid patches in the mini-pig model. J. Urol. 154: 893-898. [Medline] [CrossRef]

24. McDougal, W. S. 1992. Metabolic complications of urinary intestinal diversion. J. Urol. 147: 1199-1208. [Medline]

25. McLoughlin, M. A., Walshaw, R., Thomas, M. W. and Hauptman, J. G. 1992. Gastric conduit urinary diversion in normal dogs. Part I, Upper urinary tract structure, function, and sepsis. Vet. Surg. 21: 25-32. [Medline] [CrossRef]

26. Nguyen, D. H., Bain, M. A., Salmonson, K. L., Ganesan, G. S., Burns, M. W. and Mitchell, M. E. 1993. The syndrome of dysuria and hematuria in pediatric urinary reconstruction with stomach. J. Urol. 150: 707-709. [Medline]

27. Niknejad, K. G. and Atala, A. 2000. Bladder augmentation techniques in women. Int. Urogynecol. J. Pelvic Floor Dysfunct. 11: 156-169. [Medline] [CrossRef]

28. Nurse, D. E. and Mundy, A. R. 1989. Metabolic complications of cystoplasty. Br. J. Urol. 63: 165-170. [Medline] [CrossRef]

29. Palmer, L. S., Franco, I., Kogan, S. J., Reda, E., Gill, B. and Levitt, S. B. 1993. Urolithiasis in children following augmentation cystoplasty. J. Urol. 150: 726-729. [Medline]

30. Pozzi, A., Smeak, D. D. and Aper, R. 2006. Colonic seromuscular augmentation cystoplasty following subtotal cystectomy for treatment of bladder necrosis caused by bladder torsion in a dog. J. Am. Vet. Med. Assoc. 229: 235-239. [Medline] [CrossRef]

31. Qiu, H., Kordunskaya, S. and Yantiss, R. K. 2003. Transitional cell carcinoma arising in the gastric remnant following gastrocystoplasty a case report and review of the literature. Int. J. Surg. Pathol. 11: 143-147. [Medline] [CrossRef]

32. Seif, M. M., Aimen, M. S. and Kamel, H. H. 2007. Gastric neobladder: an experimental study in dog. Beni-Suef Vet. Med. J. 17: 50-60.

33. Sutherland, R. S., Baskin, L. S., Hayward, S. W. and Cunha, G. R. 1996. Regeneration of bladder urothelium, smooth muscle, blood vessels and nerves into an acellular tissue matrix. J. Urol. 156: 571-577. [Medline] [CrossRef] 